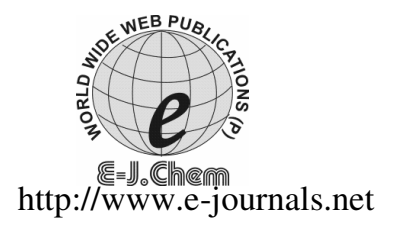

ISSN: 0973-4945; CODEN ECJHAO

E-Journal of Chemistry

2011, 8(3), 1451-1455

\title{
In Vitro Antioxidant Capacity and Neuronal Cell Toxicity of Roots of Ostericum koreanum Maximowicz
}

\author{
RAMALINGAM MAHESH ${ }^{\S}$, HYO WON JUNG \\ JUN HONG PARK ${ }^{\#}$ and YONG-KI PARK ${ }^{\S, * * *}$ \\ ${ }^{\S}$ Oriental Medicine Research Institute \\ ${ }^{\ddagger}$ Oriental Medicine R\&D Center and Department of Herbology \\ College of Oriental Medicine, Dongguk University, 707, Seokjangdong \\ Gyeongju, Gyeongbuk 780-714, Republic of Korea \\ \#Bonghwa Alpine Medicinal Plant Experiment Station \\ Gyeongsangbook-do 755-843, Republic of Korea \\ yongki@dongguk.ac.kr
}

Received 3 March 2010; Accepted 21 May 2010

\begin{abstract}
Ostericum koreanum maximowicz (Umbelliferae), a medicinal herb in Korean Oriental Medicine, has been applied to treat cold, headache, neuralgia and arthralgia. The ethyl acetate fraction of $O$. koreanum root was subjected to in vitro antioxidant activity with different methods for free radical scavenging activities. In addition, the cell viability and nitric oxide release assays were performed here for the first time in neuroblastoma (Neuro-2a) cell cultures. Among all the tested methods, the ethyl acetate fraction was expressed very active, exhibiting a good Trolox equivalent values and $\mathrm{IC}_{50}$, comparable to that of the commercial antioxidants, Trolox and ascorbic acid, respectively. The results showed that there was a reduction of cell viability by the fraction in a concentration dependent manner. These results suggest that $O$. koreanum shows good antioxidant activities in vitro by inhibiting free radicals. These findings provide a rationale for the in vivo testing. Also, the major constituents behind the antioxidant mechanisms of this fraction warrant further study.
\end{abstract}

Keywords: Antioxidant activity, Free radical scavenging, Neuro-2a, Ostericum koreanum maximowicz.

\section{Introduction}

Ostericum koreanum maximowicz (Umbelliferae) is used traditionally in Korean Oriental Medicine. The roots of $O$. koreanum have long been used to treat cold, headache, neuralgia and arthralgia in oriental medicine ${ }^{1}$. This plant is known to have many pharmacologic activities, such as anti-tumor ${ }^{2}$, anti-microbial ${ }^{3}$, antioxidant ${ }^{4}$, anti-inflammatory ${ }^{5}$ and acaricidal activity $^{6}$. It was proposed that the components responsible for these activities were isoimperatorin, oxypeucedanin, isooxypeucedanin, oxypeucedanin bergapten, osthol, oxypeucedanin hydrate, 
cnidicin, marmesinin ${ }^{7-9}$, 11-hydroxy-sec-O-glucosylhamaudol ${ }^{4}$, essential oils $^{3}$ and bisabolangelone $^{6}$. Recently, we reported that bisabolangelone isolated from $O$. koreanum inhibits the production of inflammatory mediators by down-regulation of NF- $\mathrm{KB}$ and ERK MAP kinase activity in LPS-stimulated RAW264.7 cells $^{10}$.

In the present study, the roots of $O$. koreanum ethyl acetate fraction was evaluated for Trolox equivalent antioxidant capacity (TEAC), oxygen radical absorbance capacity (ORAC), 1,1-diphenyl-2-picrylhydrazyl (DPPH) radical scavenging, superoxide radical $\left(\mathrm{O}_{2}{ }^{--}\right)$scavenging, hydrogen peroxide $\left(\mathrm{H}_{2} \mathrm{O}_{2}\right)$ scavenging, hydroxyl $\left(\mathrm{OH}^{\bullet}\right)$ radical scavenging, nitric oxide radical $\left(\mathrm{NO}^{\circ}\right)$ scavenging and ferrous ion chelating efficacies. Moreover, the effects of ethyl acetate fraction of $O$. koreanum roots on cell viability and nitric oxide (NO) release in neuro-2a (N2a) cells were analyzed.

\section{Experimental}

1,1-Diphenyl-2-picrylhydrazyl (DPPH), nitro blue tetrazolium salt (NBT), phenazine methosulfate (PMS), thiobarbituric acid (TBA), trichloroacetic acid (TCA), dimethyl sulphoxide (DMSO), sodium nitroprusside (SNP), sulphanilic acid, $N$-(1-Naphthyl) ethylenediamine dihydrochloride, ethylenediaminetetraacetic acid (EDTA), $\mathrm{FeSO}_{4} \cdot 7 \mathrm{H}_{2} \mathrm{O}$, deoxyribose, 2,2'-azino-bis(3-ethylbenzthioziozline-6-sulphonic acid (ABTS), 2,2'-azobis (2-amidinopropane) dihydrochloride (AAPH), Trolox (6-hydroxy-2,5,7,8-tetramethyl chroman-2-carboxylic acid), a water-soluble analogue of vitamin E and 3-(4,5-dimethyl-2yl)-2,5-diphenyltetrazolium bromide (MTT) were purchased from Sigma Co. (St. Louis, MO, USA). All other chemicals used were of analytical grade supplied by Fluka, Aldrich or Sigma Co.

\section{Plant material}

O. koreanum roots, cultured in Bongwha Alpine Medicinal Plant Experiment Station (BAMPES; Gyeongsangbook, Republic of Korea), were authenticated. A voucher specimen was deposited in the herbarium of BAMPES, with the registration number NK-2007-10.

\section{Extraction and fractionation}

Air-dried roots of $O$. koreanum $(1.5 \mathrm{~kg}$ ) were cut into small pieces, pulverized and extracted three times with $4.5 \mathrm{~L}$ of methanol at room temperature for $24 \mathrm{~h}$. The supernatant was collected by filtration and the solvent was evaporated under in vacuum at $40{ }^{\circ} \mathrm{C}(\sim 74 \mathrm{~g})$. The extract $(70 \mathrm{~g})$ was sequentially partitioned into hexane $(11 \mathrm{~g})$, ethyl acetate $(10 \mathrm{~g})$, $n$-butanol (14 g) and water (35 g) portions. The most active ethyl acetate fraction was used for bioassays.

\section{Antioxidant assays}

In vitro antioxidant activity was studied by $\mathrm{TEAC}^{11,12}, \mathrm{ORAC}^{13}, \mathrm{DPPH}^{14}$, superoxide radical $^{15}$, hydrogen peroxide decomposition ${ }^{16,17}$, hydroxyl radical ${ }^{18}$, nitric oxide radical inhibition ${ }^{19,20}$ and metal chelation ${ }^{21}$.

\section{Cell culture and treatments}

Neuro-2a (N2a; CCL-131, American Type Culture Collection, Manassas, VA) neuroblastoma cells were grown in Dulbecco's modified Eagle's medium (DMEM) supplemented with $10 \%$ heat inactivated fetal bovine serum (FBS) and $1 \%$ penicillinstreptomycin (Pen-Strep, GIBCO, Grand Island, NY). Cultures were maintained in a humidified atmosphere at $37^{\circ} \mathrm{C}$ with $5 \% \mathrm{CO}_{2}$. Cells were seeded and allowed to grow for $24 \mathrm{~h}$. 
For treatments, $24 \mathrm{~h}$ of serum-starved cells were incubated with $O$. koreanum ethyl acetate fraction $(2.5-30 \mu \mathrm{g} / \mathrm{mL})$ for $1 \mathrm{~h}$. Cell viability was measured by the MTT (3-(4,5-dimethyl2-yl)-2,5-diphenyltetrazolium bromide) method. The NO production was measured as the nitrite $\left(\mathrm{NO}_{2}{ }^{-}\right)$concentration. All experiments were performed a minimum of three times and P-values lower than 0.05 was considered statistically significant.

\section{Statistical analysis}

The data are expressed as the mean \pm SD of three measurements. Statistical analysis was performed using Tukey's test. $p<0.05$ was considered statistically significant.

\section{Results and Discussion}

In this study, we designed to evaluate the antioxidant and free radical scavenging activities of ethyl acetate fraction of methanol extract of $O$. koreanum roots. From results, the $O$. koreanum roots ethyl acetate fraction showed potent antioxidant activity based on TEAC, ORAC and DPPH and other free radical scavenging tests in a dose dependent manner. The O. koreanum roots were found to be active in TEAC, ORAC and DPPH as $0.516,2.884$ and 1.514 mmole Trolox equivalents per grams, respectively (Table 1). The ethyl acetate fraction showed the most efficient against TEAC followed by DPPH and ORAC. From this, the $O$. koreanum was weak in scavenging the ORAC compared to others. According to the TEAC method, this fraction acted as a direct free radical scavenger, indicating that this fraction had significant antioxidant activity. The scavenging data suggests that the components within the fraction is capable of scavenging free radicals via a mechanism of electron/hydrogen donation and should be able to protect susceptible matrices from free radical-mediated oxidative degradation.

Table 1. The antioxidant activities of ethyl acetate fraction of $O$. koreanum.

\begin{tabular}{cccc}
\hline & TEAC, $\mathrm{mM} \mathrm{TE} / \mathrm{g}$ & ORAC, $\mathrm{mM} \mathrm{TE} / \mathrm{g}$ & DPPH, $\mathrm{mM}$ TE/ g \\
\hline O. koreanum & $0.516 \pm 0.024$ & $2.884 \pm 0.148$ & $1.514 \pm 0.011$ \\
Ascorbic acid & $0.828 \pm 0.010$ & $0.030 \pm 0.018$ & $1.332 \pm 0.027$ \\
\hline
\end{tabular}

Moreover, this fraction strongly scavenged $\mathrm{O}_{2}{ }^{--}, \mathrm{H}_{2} \mathrm{O}_{2}, \mathrm{OH}^{\bullet}$ and $\mathrm{NO}^{\bullet}$ with the $\mathrm{IC}_{50}$ being 23.582, 66.310, 170.582 and 60.779 micrograms per $\mathrm{mL}$ and the activity is comparable to that of ascorbic acid. The extract also strongly chelated $\mathrm{Fe}^{3+}$ ions at 7.846 micrograms per $\mathrm{mL}$ of $\mathrm{IC}_{50}$ (Table 2). In the PMS-NADH-NBT system, superoxide anion, derived from dissolved oxygen from the coupling reaction of PMS-NADH, reduces NBT. Then, scavenging of $\mathrm{H}_{2} \mathrm{O}_{2}$ may be attributed to electrons donation to $\mathrm{H}_{2} \mathrm{O}_{2}$, thus neutralizing it to water. Although $\mathrm{H}_{2} \mathrm{O}_{2}$ itself is not very reactive, it can sometimes cause cytotoxicity by giving rise to $\mathrm{OH}^{\bullet}$ in the cell.

Table 2. The free radical scavenging and metal chelating activities $\left(\mathrm{IC}_{50} \mathrm{as} \mu \mathrm{g} / \mathrm{mL}\right)$ of ethyl acetate fraction of $O$. koreanum

\begin{tabular}{lccccc}
\hline & $\mathrm{O}_{2}{ }^{\bullet-}$ & $\mathrm{H}_{2} \mathrm{O}_{2}$ & $\mathrm{OH}^{\bullet}$ & $\mathrm{NO}^{\bullet}$ & Metal chelation \\
\hline O. koreanum & $23.582 \pm$ & $66.310 \pm$ & $170.582 \pm$ & $60.779 \pm$ & $7.846 \pm$ \\
& 4.480 & 2.653 & 7.118 & 1.568 & 1.732 \\
Ascorbic acid & $8.762 \pm$ & $8.053 \pm$ & $3.034 \pm$ & $9.885 \pm$ & $43.235 \pm$ \\
& 4.569 & 3.677 & 0.191 & 0.478 & 8.543 \\
\hline
\end{tabular}

Values are means \pm SD of three measurements. TEAC trolox equivalent antioxidant capacity, ORAC oxygen radical absorbance capacity, DPPH 1,1-diphenyl-2-picrylhydrazyl 
The $O$. koreanum fraction was evaluated for their ability to scavenge $\mathrm{OH}^{\bullet}$ using the deoxyribose degradation assay and nitric oxide radicals using sodium nitroprusside (SNP) as a $\mathrm{NO}^{\bullet}$ donor. The chelation of ferrous ions, in which ferrozine quantitatively forms complexes with $\mathrm{Fe}^{2+}$. In the presence of chelating agents, the formation of this complex is disrupted, thereby impeding the formation of the red colour imparted by the complex as well. Considering the results obtained, it may be anticipated that the ethyl acetate fraction of $O$. koreanum methanol extract have antioxidant activity, shown here by the scavenging of $\mathrm{O}_{2}{ }^{\circ-}$, $\mathrm{H}_{2} \mathrm{O}_{2}, \mathrm{OH}^{\bullet}$ and $\mathrm{NO}^{\bullet}$ and ferrous ion chelating efficacies.

To determine the effects of roots of ethyl acetate fraction of $O$. koreanum on cell viability, the $\mathrm{N} 2 \mathrm{a}$ cells were exposed to $O$. koreanum $(2.5 \sim 30 \mu \mathrm{g} / \mathrm{mL})$ for an incubation time of $1 \mathrm{~h}$. In Figure 1, the MTT test after $1 \mathrm{~h}$ of incubation with $O$. koreanum roots does not indicate any significant viability difference at 2.5 and 5.0 micrograms per $\mathrm{mL}$ in treated $\mathrm{N} 2 \mathrm{a}$ cell cultures in comparison to control. A significant decreasing of viability is observed in roots of $O$. koreanum ethyl acetate fraction at $7.5 \sim 30$ micrograms per $\mathrm{mL}$ treated $\mathrm{N} 2 \mathrm{a}$ cells in comparison to control. NO determination was performed after $1 \mathrm{~h}$ of incubation in the presence of $O$. koreanum $(2.5 \sim 30 \mu \mathrm{g} / \mathrm{mL})$. The treatment with 7.5 micrograms per $\mathrm{mL}$ of $O$. koreanum ethyl acetate fraction produces NO decrease significantly when compared to control, but other doses did not show any significant changes in NO release. From this result that the minimal doses of $O$. koreanum have no toxicity effects.
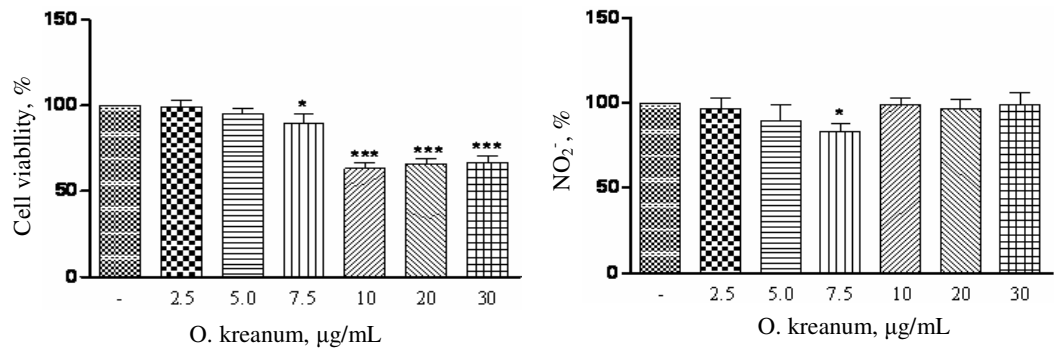

Figure 1. Effect of $O$. koreanum on cell viability and nitric oxide release in neuro-2a cells. Values are means $\pm \mathrm{SD}$ of three measurements. ${ }^{*} p<0.05,{ }^{* *} p<0.01,{ }^{* * *} p<0.001$ (ANOVA/Tukey) compared with untreated normal

\section{Conclusion}

This study demonstrates that the various free radical scavenging mechanisms of $O$. koreanum ethyl acetate fraction may be attributed to its strong abilities as a hydrogen donor. Also, the study verified the effectiveness of $O$. koreanum on cell viability and nitric oxide release in cell culture model. As a result, the medicinal claims of $O$. koreanum being used in the treatment of various diseases may be in part due to the antioxidant activity having potential in scavenging of free radicals come out for the therapeutic value. Further isolation of antioxidant constituents and in vivo antioxidant studies are warranted.

\section{Acknowledgments}

This study was supported by the research fund of Studies on the Development of Oriental Medicine for Allergic Rhinitis from Ministry of Health, Welfare \& Family Affairs (2009), Republic of Korea (to Y.-K. Park). 


\section{References}

$1 \quad$ Ryu K S and Yook C S, J Pharm Soc Korea, 1968, 12, 59-64.

2 Kang T J, Lee S Y, Singh R P, Agarwal R and Yim D S, Acta Oncol., 2009, 48, 895-900.

3 Shin S, Arch Pharm Res., 2005, 28(7), 765-769.

4 Park Y J, Kim H J, Lee S J, Choi H Y, Jin C and Lee Y S, Chem Pharm Bull., 2007, 55(7), 1065-1066.

5 Park H J, Bae G S, Kim D Y, Seo S W, Park K B, Kim B J, Song J M, Lee K Y, Na C, Shin B C, Park S J, Song H J and Hwang S Y, Kor J Herbology, 2008, 23, 127.

6 Lee C K and Woo W S, Kor J Pharmacogn., 1982, 13, 10-13.

$7 \quad$ Kwon Y S, In K K and Kim C M, Kor J Pharmacogn., 2000, 31, 284-287.

8 Ryu S Y, Kou N Y, Choi H S, Ryu H, Kim T S and Kim K M, Planta Med., 2001, 67, 172-174.

9 Kang S W, Kim H K, Lee W J and Ahn Y J, J Agric Food Chem., 2006, 54, 3547-3550.

10 Jung $\mathrm{H} \mathrm{W}$, Mahesh $\mathrm{R}$, Park $\mathrm{J} \mathrm{H}$, Boo $\mathrm{Y} \mathrm{C}$, Park $\mathrm{K} \mathrm{M}$ and Park Y K, Int Immunopharmacol., 2010, 10, 155-162.

11 Re R, Pellegrini N, Proteggente A, Pannala A, Yang M and Rice-Evans C, Free Radic Biol Med., 1999, 26, 1231-1237.

12 Schlesier K, Harwat M, Böhm V and Bitsch R, Free Radical Res., 2002, 36, 177-187.

13 Cao G, Verdon C P, Wu A H B, Wang H and Prior R L, Clin Chem., 1995, 41, 1738-1744.

14 Gyamfi M A, Yonamine M and Aniya Y, Gen Pharmacol., 1999, 32, 661-667.

15 Robak J and Gryglewski R J, Biochem Pharmacol., 1988, 36, 317.

16 Sinha A K, Anal Biochem., 1972, 47, 389-394.

17 Ohkawa H, Ohishi N and Yagi K, Anal Biochem., 1979, 95, 351-358.

18 Chung S K, Osawa T and Kawakishi S, Biosci Biotech Biochem., 1997, 61, 118-124.

19 Garratt D C, The quantitative analysis of drugs; Chapman and Hall: Japan, 1964, 3, 456-458.

20 Marcocci P L, Sckaki A and Albert G M, Methods Enzymol., 1994, 234, 462-475.

21 Decker E A and Welch B, J Agric Food Chem., 1990, 38, 674. 


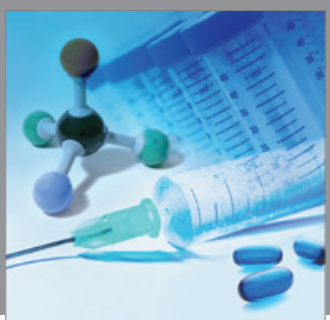

International Journal of

Medicinal Chemistry

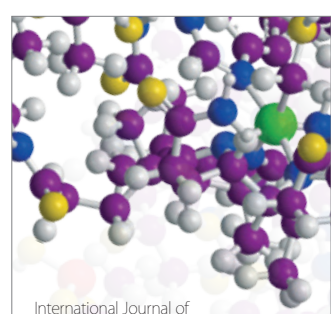

Carbohydrate Chemistry

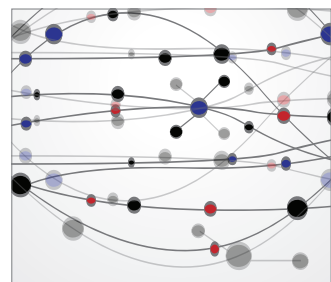

The Scientific World Journal
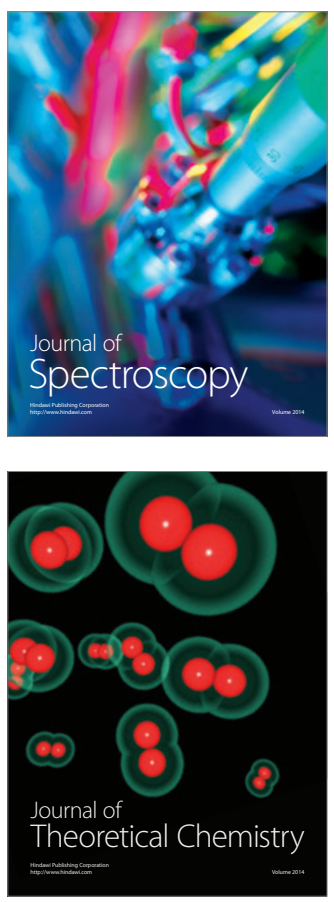
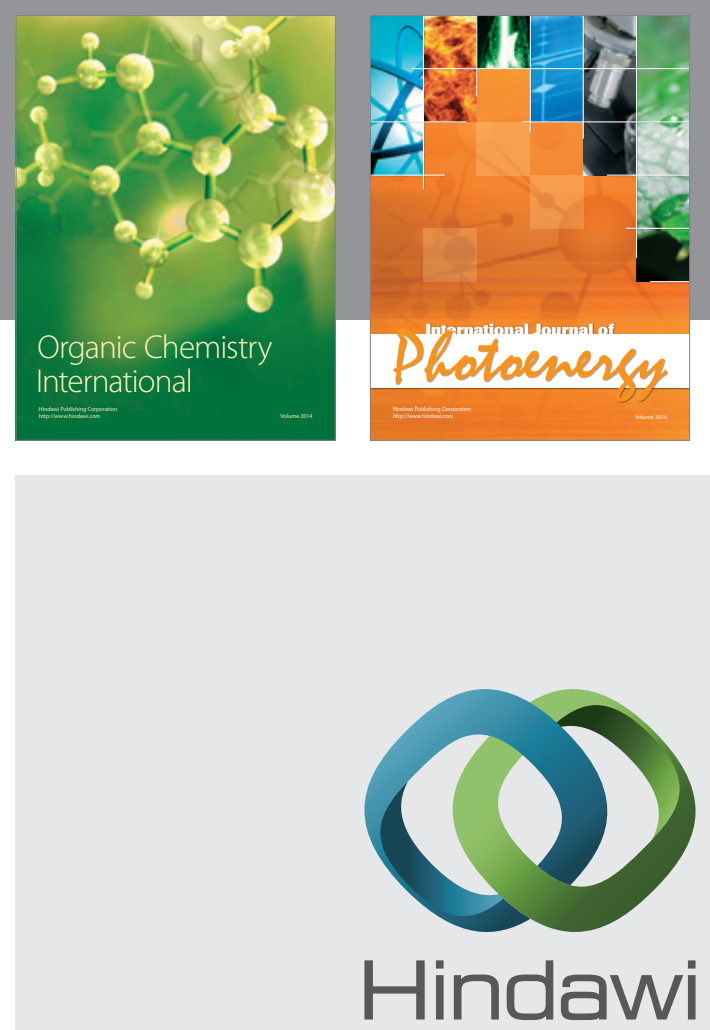

Submit your manuscripts at

http://www.hindawi.com
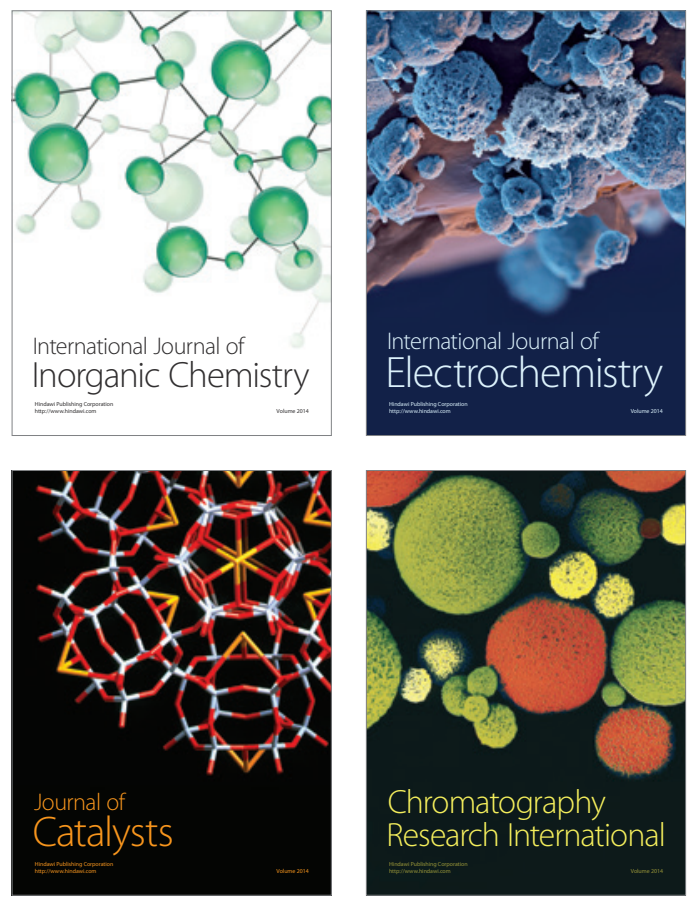
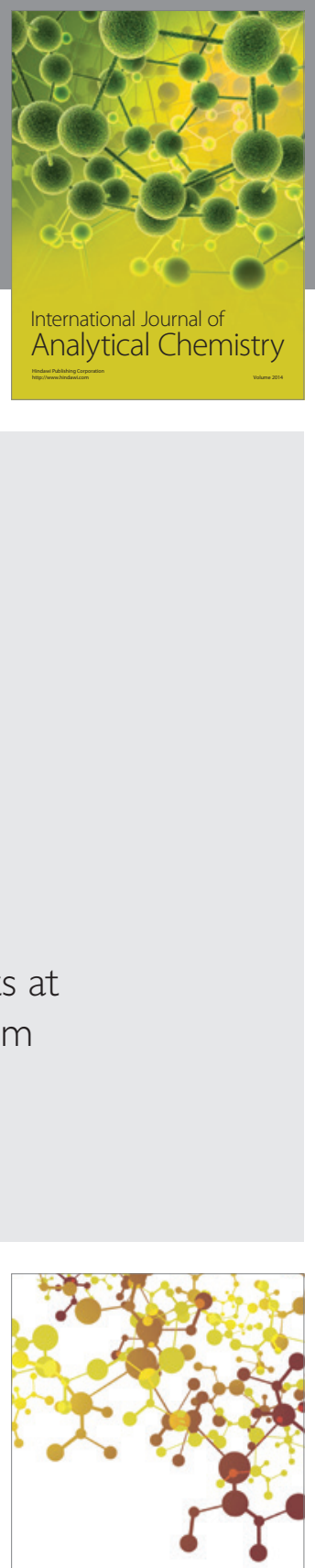

Journal of

Applied Chemistry
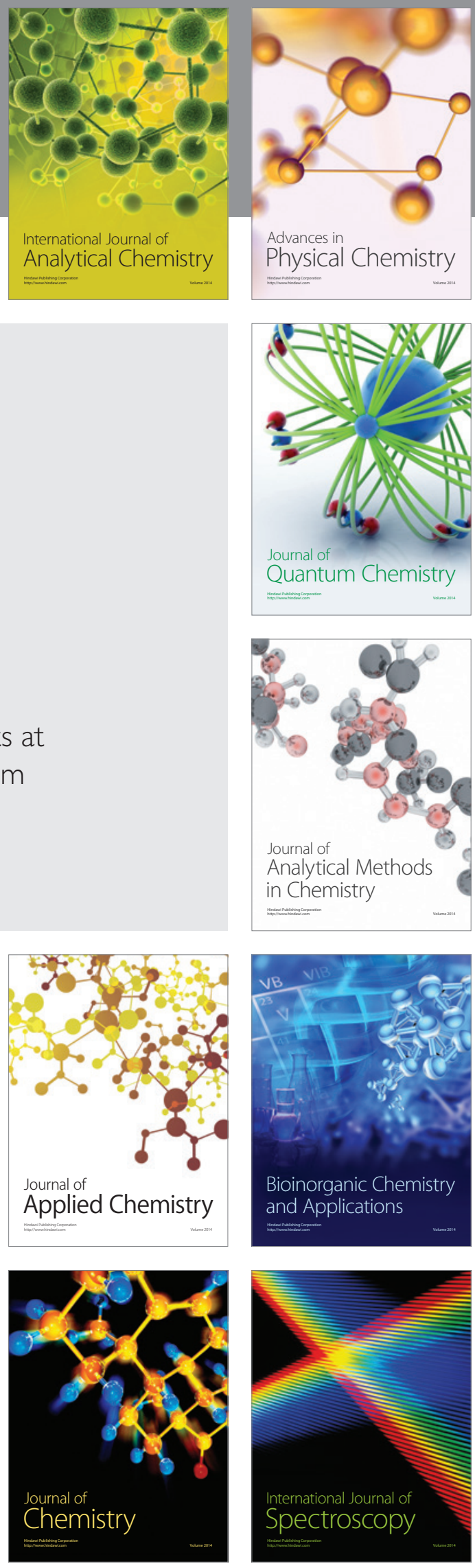